

\title{
PERBEDAAN PENGARUH ANTARA METODE DRILL DAN METODE KOMANDO TERHADAP HASIL BELAJAR TOLAK PELURU PADA SISWA KELAS VI SD NEGERI HATUSUA
}

\author{
Teddy Latue ${ }^{1}$ Jusak Syaranamual ${ }^{2}$ Johni Melvin Tahapary ${ }^{3}$ \\ jusakambon@gmail.com johnitahapary62@gmail.com
}

\begin{abstract}
ABSTRAK
Sekolah memiliki halaman yang cukup luas dan digunakan sebagai tempat bermain bagi siswa dan juga sebagai tempat proses pembelajaran pendidikan jasmani. Peralatan olahraga yang dimiliki juga sangat terbatas dan tidak mencukupi standar minimal yang dibutuhkan. Hal tersebut tidak sebanding dengan jumlah siswa yang mempunyai jumlah rata-rata 14 - 22 siswa untuk setiap kelasnya. Populasi dalam penelitian ini adalah seluruh siswa kelas VI SD Hatusua yang berjumlah 20 orang. Melihat pada jumlah populasi yang ada, maka penelitian ini adalah penelitian populasi. Berdasarkan hasil analisis yang telah dilakukan, maka terdapat perbedaan pengaruh yang signifikansi pada taraf 5\%, thitung lebih besar yaitu 2,327 dari tabel yaitu 2,10. Dengan demikian, adanya perbedaan penggunaan metode drill dan metode komando terhadap hasil belajar tolak peluru siswa kelas VI SD Negeri 1 Hatusua yang sedang diteliti itu, membawa perbedaan secara signifikan terhadap hasil belajar tolak peluru mereka.
\end{abstract}

Kata kunci: Drill, Komando, Tolak Peluru 


\section{PENDAHULUAN}

Pendidikan Jasmani merupakan salah satu pelajaran yang diajarkan kepada seluruh siswa sekolah, mulai dari tingkat dasar sampai tingkat atas. Materi pendidikan jasmani berbeda dengan materi pembelajaran yang lain, karena selain pelajaran teori, siswa-siswi juga diajarkan praktek yang berupa aktifitas jasmani atau olahraga yang disesuaikan dengan kemampuan dan karakteristik anak. Pendidikan Jasmani di sekolah merupakan bagian dari pendidikan pada umumnya, pendidikan jasmani membentuk atau membangun manusia seutuhnya dari segi lahir maupun batin. Kondisi lahir atau jasmani ini meliputi pertumbuhan fisik, perkembangan fisik, kesehatan dan rehabilitasi. Pertumbuhan dan perkembangan fisik akan lebih cepat melalui pembelajaran pendidikan jasmani, (Setiawan, 2014).

Untuk itu kebutuhan memodifikasi pembelajaran sebagai suatu pendekatan alternatif dalam pembelajaran pendidikan jasmani perlu dilakukan. Guru sebaiknya memiliki kemampuan untuk memodifikasi keterampilan yang hendak diajarkan agar sesuai dengan tingkat perkembangan siswa. Guru dituntut lebih kreatif, inovatif dalam menciptakan pembelajaran yang akan diberikan kepada siswa, sehingga tercipta pembelajaran yang aktif bagi siswa tanpa meninggalkan tujuan pembelajaran yang ingin dicapai. Berdasarkan hasil observasi awal pada siswa kelas VI SD Negeri Hatusua masih banyak siswa yang mengalami kesulitan dalam melakukan rangkaian gerakan tolak peluru. Sebagian besar siswa belum mengetahui antara melempar/menolak peluru dengan rangkaian gerakan tolak peluru dengan benar. Di samping itu, sarana dan prasarana yang dimiliki SD Negeri Hatusua kurang memadai. Sekolah memiliki halaman yang cukup luas dan digunakan sebagai tempat bermain bagi siswa dan juga sebagai tempat proses pembelajaran pendidikan jasmani. Peralatan olahraga yang dimiliki juga sangat terbatas dan tidak mencukupi standar minimal yang dibutuhkan. Hal tersebut tidak sebanding dengan jumlah siswa yang mempunyai jumlah rata-rata 14 - 22 siswa untuk setiap kelasnya.

Permasalahan tersebut menggugah guru dalam hal ini peneliti, untuk memberikan respon positif secara nyata dan objektif yang dapat diwujudkan dalam upaya meningkatkan hasil belajar siswa dalam kegiatan pembelajaran tolak peluru dengan perasaan senang, bebas, terkendali dan terarah tanpa merasa ada tekanan dari luar, sehingga tercipta kemandirian belajar pada diri siswa. Atas dasar pemikiran dan kenyataan diatas, maka diperlukan adanya tindakan pemecahan masalah dalam proses pembelajaran tolak peluru gaya linear dengan penelitian tindakan kelas. Bagi guru, tindakan ini merupakan bentuk pencurahan segala perhatiannya terhadap aktivitas siswa dalam pembelajaran.

(José Manuel Ballesteros, 1984) mengatakan dalam penolak peluru harus dimulai dari sikap berdiri, berhenti seimbang dalam lingkaran tolak (tanpa menginjak garis belakang). Pelempar tidak boleh meninggalkan lingkaran dalam posisi berdiri melalui setengah lingkaran bagian belakang. 
Tolak peluru dilakukan dari sebuah lingkaran berdiameter sebesar 2, $13 \mathrm{~m}$ dengan sebuah stop watch terpasang di depannya, tolakan dilakukan setinggi bahu. Dengan melakukan satu tangan, peluru dipegang sedekat mungkin dengan bahu tidak di pundak. Pada nomor tolak peluru dikenal ada dua gaya yaitu:

a. Tolak peluru dengan gaya menyimpang

b. Tolak peluru dengan gaya membelakangi arah tolakan

tolak peluru adalah jumlah tolakan yang dilakukan oleh seorang dengan tetepatan maksimal dan mempergunakan teknik tolakan yang baik dan benar (James, 1985)Berdasarkan pendapat para ahli tersebut maka dapat disimpulkan bahwa tolak peluru adalah salah satu nomor dalam cabang olahraga atletik, yaitu nomor lempar namun pada saat melepaskan peluru, peluru tersebut tidak dilempar namun ditolakan untuk menghasilkan hasil yang diukur dengan satuan meter atau jarak.

Menurut (Roji, 2007) ada dua macam gaya yang sering digunakan pada tolak peluru, yaitu gaya lama atau gaya Ortodoks adalah teknik menolak peluru dengan gaya menyamping arah sektor tolakan dan yang kedua adalah gaya O'Brien. yaitu teknik menolak peluru dengan gaya membelakangi arah sektor tolakan yang pertama kali diperkenalkan oleh Parri O'Brien.

(sugiyono, 2014), pengertian dari metode drill adalah cara pendekatan dalam mengajar gerakan dimana siswa atau atlet diinstruksikan melakukan gerakan tertentu berulang-ulang berdasarkan petunjuk yang diberikan oleh guru atau pelatih. Siswa atau atlet harus memperhatikan bentuk gerakan dan prosedur pelaksanaannya yang berorientasi pada guru. (Sudjana, 1990), metode drill adalah satu kegiatan melakukan hal yang sama, berulangulang secara sungguh-sungguh dengan tujuan untuk menyempurnakan suatu ketrampilan agar menjadi permanen. Ciri yang khas dari metode ini adalah kegiatan berupa pengulangan yang berkali-kali dari suatu hal yang sama.

Metode pembelajaran adalah serangkaian dan keseluruhan tindakan strategis guru dalam merealisasikan perwujudan kegiatan pembelajaran aktual yang efektif dan efisien, untuk pencapaian tujuan pembelajaran. Gaya pembelajaran merupakan sebagian dari keseluruhan komponen pembelajaran. Metode pembelajaran berhubungan dengan cara-cara yang dipilih guru untuk menyampaikan materi pembelajaran (Asmani, 2011).

Metode pembelalajaran komando pada prinsipnya adalah pendekatan mengajar bergantung pada guru. Guru menyiapkan semua aspek pengajaran sepenuhnya bertanggung jawab dan berinisiatif terhadap pengajaran dan memantau kemajuan belajar (Purwaningsih, 2009)

Menurut (Purwaningsih, 2009) metode komando sebagai metode yang wajib dipraktekan oleh semua mahasiswa, untuk semua materi atau pokok bahasan. metode komando dilakukan oleh setiap mahasiswa praktekan dengan materi yang berbeda yang terdiri atas: permainan, senam dan atletik, dengan memperhatikan jadwal atau acuan dalam GBPP bidang studi pendidikan jasmani, untuk strata kelas yang di ajar oleh mahasiswa praktikan yang bersangkutan. Guru yang membuat keputusan tentang bentuk, tempo, urutan, intensitas, penilaian dan tujuan proses belajar mengajar. Kebebasan siswa sangat terbatas hanya kepada mau atau tidaknya mengikuti dan mematuhi perintah guru. 
Belajar merupakan aktivitas manusia yang sangat vital dan secara terus menerus akan dilakukan selama manusia hidup. Manusia tidak mampu hidup jika ia tidak di didik atau diajar oleh manusia lainnya. Belajar adalah kegiatan individu memperoleh pengetahuan, perilaku dan keterampilan dengan cara mengolah bahan ajar (Purwaningsih, 2009). Belajar adalah proses mental yang terjadi dalam diri sesorang, sehingga menyebabkan munculnya perubahan tingkah laku.

(Sugihartono, 2007) mengemukakan bahwa bahwa belajar adalah suatu proses perubahan tingkah laku sebagai hsil interaksi individu dengan lingkungannya dalam memenuhi kebutuhan hidupnya. Berdasarkan defenisi diatas maka dapat ditarik kesimpulan bahwa belajar adalah proses perubahan tingkah l;aku setelah berinteraksi dengan lingkungannya, baik lingkungan sekolah maupun lingkungan masyarakat yang akan menambah pengetahuan, keterampilan, maupun sikap.

Dalam sistem pendidikan nasional rumusan tujuan pendidikan, baik tujuan kurikuler maupun tujuan instruksional, menggunakan klasifikasi hasil belajar dari Benyamin (Sudjana, 1990) yang secara garis besar membaginya menjadi tiga ranah, yaitu ranah kognitif, ranah afektif, dan ranah psikomotor.

(Sugihartono, 2007)mengungkapkan bahwa hasil belajar merupakan kemampuan-kemampuan yang dimiliki siswa setelah ia menerima pengalaman belajarnya. Hasil belajar adalah pola-pola perbuatan, nilai-nilai, pengertianpengertian, sikap-sikap, apresiasi dan keterampilan. (Winkel, 1996), menyampaikan 3 taksonomi yang disebut dengan ranah belajar yaitu: ranah kognitif (cognitive domain), ranah afektif (affective domain) dan ranah psikomotorik ( psychomotoric domain).

\section{METODE}

1. Rancangan Penelitian

Penelitian ini adalah penelitian Tindakan Kelas (PTK) eksperimen lapangan yakni untuk melihat terdapat perbedaan pengaruh antara metode drill dan metode komando terhadap hasil belajar tolak peluru pada siswa kelas VI SD Negeri Hatusua. Rancangan penelitian yang digunakan dalam penelitian ini adalah rancangan One Group Pree Test Post Test Design, (Suryabrata, 2011)

\begin{tabular}{|c|c|c|}
\hline To & $X$ & $T 1$ \\
\hline
\end{tabular}

Gambar : 3.1 DesainPree test post test (Suryabrata, 2011)

2. Variabel Penelitian

a. variabel bebas $X$ adalah pengaruh metode drill dan metode Metode komando dengan indikatornya RPP tolak peluru

b. variabel terikat $Y$ adalah hasil belajar tolak peluru

3. Populasi dan sampel

Populasi dalam penelitian ini adalah seluruh siswa kelas VI SD Hatusua yang berjumlah 20 orang. Melihat pada jumlah populasi yang ada, maka penelitian ini adalah penelitian populasi.

4. Instrumen Penelitian 

a. RPP (rancangan proses pembelajaran)
b. Tes tolak peluru (Carr, 1997)

\section{Teknik Pengumpulan Data}

Dalam melaksanakan penelitian digunakan teknik pengumpulan data dengan langkah- langkah sebagai berikut:

a. Prosedur administrasi

1) surat permohonan izin penelitian

2) mempersipkan lokasi dan sampel penelitian

3) mempersiapkan alat dan fasilitas penelitian

4) mempersiapkan tenaga pembantu

5) melakukan pendataan terhadap populasi yang akan di teliti

b. Prosedur pembelajaran

Menggunakan langkah-langkah dalam RPP yang terdiri atas pendahuluan, inti dan penutup.

c. Alat dan fasilitas
1) sempritan
2) peluru
3) lapangan tolak peluru
4) format penilaian
5) alat tulis menulis

d. Prosedur kerja

1) Mempersiapkan lokasi penelitian dan sampel

2) Mempersiapkan tenaga pembantu dalam pelaksanaan penelitian

3) Memberikan penjelasan kepada sampel tentang maksud penelitian

4) Pelaksanaan pretest

5) Proses perlakuan dilaksanakan mengikuti jumlah pertemuan yang telah diprogramkan dalam program semester untuk sub-pokok bahasan atletik tolak peluru. Jumlah pertemuan dilakukan sebanyak 4 kali dengan srtategi 2 kali dalam pertemuan jam formal dan 2 kali dalam pertemuan ekstrakurikuler.

6) Pelaksanaan pos test

7) setelah data terkumpul kemudian di analisis menggunakan analisis deskriftif

e. Pelaksanaan Tes tolak Peluru

1) Setiap sampel diberikan kesempatan 3 kali tolakan

2) Dari 3 kali tolakan diambil yang terjauh

3) Pengukuran dilakukan dengan cara meletakan alat ukur pada angka nol di titik terdekat jatuhnya peluru dengan batas awalan kemudian ditarik ke arah tengah lingkaran. Setelah itu diukur berapa panjang antara titik terdekat jatuhnya peluru yang terdekat dengan batas awalan sampai dengan batas awalan. 
4) Dicatat sebagai data

6. Teknik Analisa Data

Data yang diperoleh akan diperoleh akan dianalisis dangan menggunakan rumus uji-t (Anas, 2009) dengan langkah-langkah sebagai berikut:

$t_{o}=\frac{M_{1}-M_{2}}{S E_{M_{1}-M_{2}}}$

Keterangan:

$\mathrm{M}_{1}=$ Mean Variabel X

$\mathrm{M}_{2}=$ Mean variabel $\mathrm{Y}$

$\mathrm{SE}=$ Standar ErrorMean perbedaan variabel $\mathrm{X}$ dan variabel

\begin{tabular}{|c|c|c|c|c|c|c|}
\hline No & $\mathbf{X}$ & $\mathbf{Y}$ & $\mathbf{X}$ & $\mathbf{y}$ & $\mathbf{X}^{\mathbf{2}}$ & $\mathbf{y}^{\mathbf{2}}$ \\
\hline 1. & 3.6 & 3.6 & -0.1 & 0.37 & 0.01 & 0.14 \\
\hline 2. & 3.4 & 2.7 & -0.3 & -0.53 & 0.09 & 0.28 \\
\hline 3. & 3.4 & 2.7 & -0.3 & -0.53 & 0.09 & 0.28 \\
\hline 4. & 3.8 & 4.2 & 0.1 & 0.97 & 0.01 & 0.94 \\
\hline 5. & 4 & 2.8 & 0.3 & -0.43 & 0.09 & 0.18 \\
\hline 6. & 3.2 & 3 & -0.5 & -0.23 & 0.25 & 0.05 \\
\hline 7. & 4.3 & 3 & 0.6 & -0.23 & 0.36 & 0.05 \\
\hline 8. & 3.8 & 3.8 & 0.1 & 0.57 & 0.01 & 0.32 \\
\hline 9. & 4.2 & 3.5 & 0.5 & 0.27 & 0.25 & 0.07 \\
\hline 10. & 3.3 & 3 & -0.4 & -0.23 & 0.16 & 0.05 \\
\hline $\mathbf{N}=10$ & $\sum \mathrm{X}=\mathbf{3 , 7}$ & $\sum \mathrm{Y}=\mathbf{3 2 , 3}$ & $\sum \mathrm{x}=\mathbf{0}$ & $\sum \mathrm{y}=\mathbf{0}$ & $\sum \mathrm{X}^{2}=\mathbf{3 , 7}$ & $\sum \mathrm{Y}^{2}=\mathbf{3 2 , 3}$ \\
\hline
\end{tabular}

1. Mencari Mean Variabel I (Variabel X)

$$
M_{x} \text { atau } M_{1}=\frac{\sum X}{N}=\frac{37}{10}=3,7
$$

2. Mencari Mean Variabel II (Variabel $Y$ )

$$
M_{y} \text { atau } M_{2}=\frac{\sum Y}{N}=\frac{32,3}{10}=3,23
$$

3. Mencari Deviasi Standar Skor Variabel X

$$
S D_{x} \text { atau } S D_{1}=\sqrt{\frac{\sum x^{2}}{N_{1}}}=\sqrt{\frac{1.32}{10}}=\sqrt{0,132}=0,363
$$

4. Mencari Deviasi Standar Skor Variabel $Y$ 
$S D_{y}$ atau $S D_{2}=\sqrt{\frac{\sum y^{2}}{N_{2}}}=\sqrt{\frac{2,36}{10}}=\sqrt{0,236}=0,486$

5. Mencari Standard Error Mean Variabel X

$S D_{M_{x}}$ atau $S E_{M_{1}}=\frac{S D_{1}}{\sqrt{N_{1}-1}}=\frac{0,363}{\sqrt{10-1}}=\frac{0,363}{\sqrt{9}}=\frac{0,363}{3}=0,121$

6. Mencari Standar Error Mean Variabel $Y$

$S D_{M_{y}}$ atau $S E_{M_{2}}=\frac{S D_{2}}{\sqrt{N_{2}-1}}=\frac{0,486}{\sqrt{10-1}}=\frac{0,486}{\sqrt{9}}=\frac{0,486}{3}=0,162$

7. Mencari Standar Error Perbedaan antara Mean Variabel $X$ dan Mean Variabel $Y$

$$
\begin{aligned}
& S E_{M_{1}-M_{2}}=\sqrt{S E_{M_{1}}{ }^{2}+S E_{M_{2}}{ }^{2}}=\sqrt{0,121^{2}+0,162^{2}}=\sqrt{0,015+0,026} \\
& =\sqrt{0,041}=0,202
\end{aligned}
$$

8. Mencari to dengan rumus:

$$
\begin{aligned}
t_{o} & =\frac{M_{1}-M_{2}}{S E_{M_{1}-M_{2}}} \\
& =\frac{3,7-3,23}{0,202} \\
& =\frac{0,47}{0,202} \\
& =2,326732673
\end{aligned}
$$

Jadi, $t_{o}=2,327$

Berdasarkan hasil analisis yang telah dilakukan, maka terdapat perbedaan pengaruh yang signifikansi pada taraf $5 \%$, thitung lebih besar yaitu 2,327 dari tabel yaitu 2,10. Dengan demikian, adanya perbedaan penggunaan metode drill dan metode komando terhadap hasil belajar tolak peluru siswa kelas VI SD Negeri 1 Hatusua yang sedang diteliti itu, membawa perbedaan secara signifikan terhadap hasil belajar tolak peluru mereka.

Tolak peluru adalah salah satu nomor dalam cabang olahraga atletik, yaitu nomor lempar namun pada saat melepaskan peluru, peluru tersebut tidak dilempar namun ditolakan untuk menghasilkan hasil yang diukur dengan satuan meter atau jarak. Untuk mendapat hasil tolakan yang optimal dalam tolak peluru maka cara memegang peluru merupakan salah satu faktor yang sangat penting untuk diperhatikan. Selain cara memegang peluru diperlukan awalan, yaitu cara menyamping maupun membelakangi arah tolakan. Tolak peluru dengan gaya menyamping adalah menolak peluru dengan cara tidak menghadap ke arah sektor tolakan namun penolak harus berusaha untuk tidak melewati batas tolakan agar tidak didiskualifikasi. 


\section{DAFTAR PUSTAKA}

Anas, S. (2009). Pengantar Statistik Pendidikan. Rajawali Pres.

Asmani. (2011). Tuntunan Lengkap Metodologi Praktis Penelitian Pendidikan.

Carr, G. A. (1997). Atletik untuk sekolah. Raja Grafindo.

James, W. (1985). The varieties of religious experience (Vol. 15). Harvard University Press.

José Manuel Ballesteros. (1984). Track and Field Athletics: A Basic Coaching Manual.

Purwaningsih, N. (2009). Perjuangan komando daerah muria tahun 1948 sebagai pengembangan materi pembelajaran IPS Sejarah di SMP Wilayah Kabupaten Kudus. UNS (Sebelas Maret University).

Roji. (2007). bugar dengan Olahraga.

Setiawan, H. (2014). Upaya Meningkatkan Hasil Belajar Tolak Peluru Dengan Menggunakan Gaya Ortodoks Melalaui Media Audio Visual Pada Siswa Kelas VIII SMP Negeri 1 Hinai TP 2013-2014. UNIMED.

Sudjana, N. (1990). Teori-teori belajar untuk pengajaran.

Sugihartono. (2007). Jurnal Pendidikan DWIJA UTAMA.

sugiyono. (2014). statistika untuk penelitian (sugiyono (ed.)). alfabeta.

Suryabrata, S. (2011). Metodologi penelitian. Rajawali Pers.

Winkel, W. S. (1996). Psikologi pengajaran. Grasindo. 